Science \& Engineering A

Elsevier Editorial System(tm) for Materials

Manuscript Draft

Manuscript Number: MSEA-D-16-02351R1

Title: Hall- Petch strengthening of the constrained metallic binder in WC-Co cemented carbides: Experimental assessment by means of massive nanoindentation and statistical analysis

Article Type: Research Paper

Keywords: nanoindentation; composites; Hall-Petch relationship; phase boundary strengthening

Corresponding Author: Dr. JOAN JOSEP ROA ROVIRA, PhD

Corresponding Author's Institution: Universidad Politecnica de Cataluña

First Author: JOAN JOSEP ROA ROVIRA, PhD

Order of Authors: JOAN JOSEP ROA ROVIRA, PhD; E. Jiménez Piqué; J. M. Tarragó; D.A. Sandoval; A.M. Mateo; J. Fair; L. Llanes

Abstract: WC-Co cemented carbides are composites constituted for two interpenetrating networks. In this work, it is attempted by combining massive nanoindentation, statistical analysis, and implementation of a thin film model for deconvolution of the intrinsic hardness and flow stress of the metallic phase. Plotting of the experimentally data as a function of the binder mean free path results in a Hall-Petch strengthening relationship with a slope (ky) of $0.98 \mathrm{MPa} m 1 / 2$. This value points out the effectiveness of WC-Co phase boundaries as strong obstacles to slip propagation; and thus, for toughening of brittle phase by means of crack-bridging ductile reinforcement. 
Materials Science and Engineering A

Editor

Barcelona, June $10^{\text {th }} 2016$

Dear editor

Enclosed please find the manuscript entitled "Hall-Petch strengthening of the constrained metallic binder in WC-Co cemented carbides: Experimental assessment by means of massive nanoindentation and statistical analysis" to be considered for its publication in Materials Science and Engineering A. I hereby declare that this work is original and not intended for submission elsewhere.

I believe that this paper will be of interest for the community of researchers working on hardmetals because it implement a method by using massive nanoindentation and thin film models to extract the intrinsic hardness for the metallic constrained binder and extract the Hall-Petch parameters.

Thank you in advance for taking into consideration.

Looking forward hearing from you,

Yours sincerely

Dr. J. J. Roa 


\section{Ms. Ref. No.: MSEA-D-16-02351}

Title: Hall-Petch strengthening of the constrained metallic binder in WCCo cemented carbides: Experimental assessment by means of massive Nanoindentation and statistical analysis.

Dear Professor E. J. Lavernia,

Thank you for your email of July 23 informing about your positive consideration for publication of the referred manuscript, upon completion of mandatory revisions, in Materials Science and Engineering - A. From the report appended in your email, it seems that the reviewer has read the paper carefully. Please thank him for his care and criticism. As requested, we have considered the indicated comments, and our responses (and modifications - red color text in the revised version) are as follows:

Reviewer\#1's comments (RC): The idea of this paper is good and the paper deserves to be published in MSEA but after the addition of the mathematical equations used in treating the data.

RC1.- The introduction need to be re-polished carefully from two points: a) Conversion of long statement to short one, and b) Simplify the statements. Example: There are some long statements and it is prefer to be shortened for example, in the introduction, "Within this evolution trend, although the intrinsic....for enhancing material performance", This statement need to be shortened and to be simplified.

Response: We agree with this comment and the introduction has been re-polished following the comments mentioned by the reviewer as it is presented below:

WC-Co cemented carbides, usually referred to as hardmetals, are established forefront materials for tools, structural components and wear parts with stringent requirements. They exhibit an exceptional combination of strength, toughness and wear resistance as a result of the extremely different properties of their two interpenetrating constitutive phases: hard, brittle carbides and a soft, ductile metallic binder. Historically, the ever increasing implementation of hardmetals has mainly taken place on the basis of replacement of steels in machining tools. Main reasons for it are the higher hardness 
and improved wear resistance at tool tip temperatures of the former, as compared to those of the latter. However, the range of applications for cemented carbides is (and attempts to be) much wider: from tools used for drilling and mining operations, though dies employed in the forging and stamping industries, to precision parts used in the medical, electronic, aerospace and automobile industries. Within this evolution trend, most of their emerging and/or to be consolidated applications require a higher relevance of toughness, relative to that of hardness, for enhancing material performance. In this regard, the flow stress of the constrained metallic phase is a key parameter in the effective toughening of cemented carbides [1-5]. However, direct measurement of such mechanical parameter, e.g. by nanoindentation, is not trivial. On the one hand, effective yield stress of the binder is strongly dependent on the constrainment from the hard particles. On the other hand, the effective length scale (submicrometric) of the metallic phase is quite small and the geometry of the WC is complex. Therefore, when directly probing the metallic phase by nanoindentation, the contribution of the hard phase becomes unclear, as the amount of cobalt under the indentation is unknown.

In this work, microstructural effects on the flow stress of the constrained metallic binder within different hardmetal grades are studied. It is done on the basis that experimental and statistical nanoindentation techniques can be successfully implemented for assessment and analysis of the small-scale properties intrinsic to the constitutive phases of WC-Co cemented carbides. Such approach has, been recently validated for WC-Co cemented carbides by the authors of this study [6]. Statistical analysis of the experimental data is followed by deconvolution of the influence of the hard phase on the average values measured for the soft one, by using an established thin film model. Yield stress of the constrained binder is then calculated through simple conversion of the intrinsic hardness measured for this phase. Finally, a Hall-Petch relationship is assessed for the flow stress determined for the constrained binder, using the binder mean free path as the effective microstructural length scale for studying phase boundary strengthening. 


\section{RC2.- It is better to subtitle like theoretical background or mathematical treatment in the experimental procedure, Under this subtitle, add all the equations used in the treatment of the data. The references are not sufficient. Equations supported by reference will strength this paper.}

Response: From the comment proposed by the reviewer, the authors agree with this comment and the equations have been implemented in the experimental part as follows:

Before testing, each surface was polished with diamond paste down to $3 \mu \mathrm{m}$, with a final polishing step with colloidal silica. Nanoindentation tests were performed on a Nanoindenter XP (MTS) with a fully calibrated Berkovich tip, and the obtained data were analyzed using the Oliver and Pharr method [10,11]. Massive nanoindentation (1400 imprints) was performed in each material in an array, at $200 \mathrm{~nm}$ of maximum displacement into surface. Every 200 indentations, tip shape quality was contrasted with a fused silica standard. The distance between imprints was kept constant and equal to $5 \mu \mathrm{m}$ in order to avoid any overlapping effect between them. Such conditions guarantee that each individual test could be treated as an independent statistical event, as results were neither affected by indentation size effects nor by overlapping [6]. Observation of the imprints was done in a JEOL-7001F FESEM.

Data was treated according to the statistical method proposed by Ulm and coworkers [12-15]. Theoretical framework behind this approach is based on considering a sample composed by several $i$ distinct phases with different mechanical properties. Within this context, cemented carbides were deemed to be effectively heterogeneous materials at the microstructure scale, i.e. consisting of three phases defined by either different chemical nature (carbides and binder) or distinct carbide crystal orientation (i.e. with surface normal perpendicular to either basal or prismatic planes) [6]. In this regard, it is important to underline that the residual imprint is smaller than the size of the mean free path, as well as individual WC grains, allowing isolate the mechanical response for

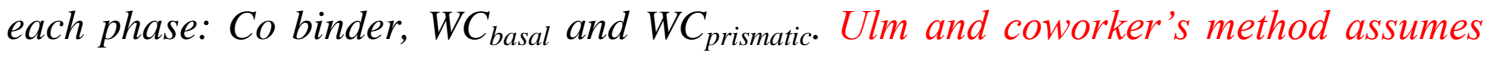
then that distribution $\left(p_{i}\right)$ of the mechanical properties $(H)$ of each phase follows a Gaussian distribution as follows:

$$
p_{i}=\frac{1}{\sqrt{2 \pi \sigma_{i}^{2}}} e^{\left(-\frac{\left[H-H_{i}\right]^{2}}{2 \sigma_{i}^{2}}\right)}
$$


where $\sigma_{i}$ is the standard deviation and $H_{i}$ is the arithmetic mean for each of the number of indentations $\left(N_{i}\right)$ done on the material phases $(i)$. Then, the cumulative distribution function (CDF) using a special sigmoidal shape error function can be written as follows:

$$
C D F=\sum_{i} \frac{1}{2} f_{i} \operatorname{erf}\left(\frac{H-H_{i}}{\sqrt{2} \sigma_{i}}\right)
$$

The fitting process was programmed to be completed when $\chi^{2}$ tolerance was less than 1 $x 10^{-15}$, with a final coefficient of determination $\left(R^{2}\right)$ value higher than 0.99.

Finally, it should be noticed that length scale ratio between nanoindentation depth and binder mean free path is relatively high (about 0.5). Thus, surrounding carbides are expected to affect small-scale properties determined for the metallic phase. Accordingly, reliable assessment of the intrinsic hardness for the constrained cobalt requires its deconvolution from the values determined above. It was done by implementing the thin film model proposed by Korsunsky et al. [16], under consideration of the binder as a layer deposited onto a carbide particle, according to:

$$
H_{C}=H_{S}+\frac{H_{f}-H_{S}}{1+k \beta^{2}}
$$

where $H_{c}$ (WC-Co composite), $H_{f}\left(\right.$ Co binder) and $H_{s}($ WC particle) are the composite, film and substrate hardness, respectively; while $\beta$ is the relative indentation depth and $k$ is a constant related to the film thickness. It permits to extract intrinsic harness values for the constrained cobalt binder, without the influence of the surrounding WC particles. 
RC3.- WC/Co composites are not standard and the quality of these products changes from manufacturer to another. Therefore, the information about the processing technique used starting from powder, forming techniques and sintering are necessary because the comparing of the data with literature could not be correct.

Response: We agree with this comment and following the suggestion of the reviewer, the experimental section related to the samples preparation has been re-written as follows:

Four microstructurally different WC-Co composites were supplied by Sandvik Hyperion (Coventry, United Kingdom). Materials were made using conventional laboratory based powder metallurgy methods. Powders were initially mixed in $100 \mathrm{~g}$ batches in $0.25 \mathrm{l}$ carbide lined mills using WC and Co metal powders in the appropriate ratio. They were ball milled during 8 hours, and then pressed into compacts of dimensions $25 \mathrm{~mm} \times 5$ mm $x 5$ mm approximately. Finally, they were sinter-HIPed at 30 bar and $1410^{\circ} \mathrm{C}$.

I would like to thank you again for your consideration of this manuscript. We hope that revised version is now completely satisfactory for final publication of our contribution. Nevertheless, please do not hesitate to contact me in case of additional doubts or queries.

Sincerely yours,

Joan Josep Roa 


\title{
Hall- Petch strengthening of the constrained metallic binder in WC-Co cemented carbides: Experimental assessment by means of massive nanoindentation and statistical analysis
}

\author{
J. J. Roa ${ }^{1,2, *}$ E. Jiménez-Piqué ${ }^{1,2}$, J. M. Tarragó ${ }^{1,2}$, D. A. Sandoval ${ }^{1,2}$, A. Mateo ${ }^{1,2}$, J. \\ Fair $^{3}$, L. Llanes ${ }^{1,2}$ \\ ${ }^{1}$ CIEFMA-Departament de Ciència del Materials i Enginyeria Metal·lúrgica, \\ Universitat Politècnica de Catalunya, Campus Diagonal Besòs (EEBE). 08019 \\ Barcelona, Spain \\ ${ }^{2}$ CRnE, Universitat Politècnica de Catalunya, Campus Diagonal Besòs (EEBE). 08019 \\ Barcelona, Spain \\ ${ }^{3}$ Sandvik Hyperion, Coventry CV4 0XG, United Kingdom \\ * Corresponding author, e-mail: joan.josep.roa@upc.edu \\ Phone: +34 9340107 21; Fax: +34 934016706
}

\begin{abstract}
WC-Co cemented carbides are composites constituted for two interpenetrating networks. In this work, it is attempted by combining massive nanoindentation, statistical analysis, and implementation of a thin film model for deconvolution of the intrinsic hardness and flow stress of the metallic phase. Plotting of the experimentally data as a function of the binder mean free path results in a Hall-Petch strengthening relationship with a slope $\left(k_{y}\right)$ of $0.98 \mathrm{MPa} \cdot \mathrm{m}^{1 / 2}$. This value points out the effectiveness of WC-Co phase boundaries as strong obstacles to slip propagation; and thus, for toughening of brittle phase by means of crack-bridging ductile reinforcement.
\end{abstract}

Keywords: nanoindentation; composites; Hall-Petch relationship; phase boundary strengthening

\section{Introduction}

WC-Co cemented carbides, usually referred to as hardmetals, are established forefront materials for tools, structural components and wear parts with stringent requirements. They exhibit an exceptional combination of strength, toughness and wear resistance as a result of the extremely different properties of their two interpenetrating constitutive 
phases: hard, brittle carbides and a soft, ductile metallic binder. Historically, the ever increasing implementation of hardmetals has mainly taken place on the basis of replacement of steels in machining tools. Main reasons for it are the higher hardness and improved wear resistance at tool tip temperatures of the former, as compared to those of the latter. However, the range of applications for cemented carbides is (and attempts to be) much wider: from tools used for drilling and mining operations, though dies employed in the forging and stamping industries, to precision parts used in the medical, electronic, aerospace and automobile industries. Within this evolution trend, most of their emerging and/or to be consolidated applications require a higher relevance of toughness, relative to that of hardness, for enhancing material performance. In this regard, the flow stress of the constrained metallic phase is a key parameter in the effective toughening of cemented carbides [1-5]. However, direct measurement of such mechanical parameter, e.g. by nanoindentation, is not trivial. On the one hand, effective yield stress of the binder is strongly dependent on the constrainment from the hard particles. On the other hand, the effective length scale (submicrometric) of the metallic phase is quite small and the geometry of the WC is complex. Therefore, when directly probing the metallic phase by nanoindentation, the contribution of the hard phase becomes unclear, as the amount of cobalt under the indentation is unknown.

In this work, microstructural effects on the flow stress of the constrained metallic binder within different hardmetal grades are studied. It is done on the basis that experimental and statistical nanoindentation techniques can be successfully implemented for assessment and analysis of the small-scale properties intrinsic to the constitutive phases of WC-Co cemented carbides. Such approach has, been recently validated for WC-Co cemented carbides by the authors of this study [6]. Statistical analysis of the experimental data is followed by deconvolution of the influence of the hard phase on the average values measured for the soft one, by using an established thin film model. Yield stress of the constrained binder is then calculated through simple conversion of the intrinsic hardness measured for this phase. Finally, a Hall-Petch relationship is assessed for the flow stress determined for the constrained binder, using the binder mean free path as the effective microstructural length scale for studying phase boundary strengthening.

\section{Experimental procedure}


Four microstructurally different WC-Co composites were supplied by Sandvik Hyperion (Coventry, United Kingdom). Materials were made using conventional laboratory based powder metallurgy methods. Powders were initially mixed in $100 \mathrm{~g}$ batches in 0.251 carbide lined mills using WC and Co metal powders in the appropriate ratio. They were ball milled during 8 hours, and then pressed into compacts of dimensions $25 \mathrm{~mm}$ x $5 \mathrm{~mm}$ x $5 \mathrm{~mm}$ approximately. Finally, they were sinter-HIPed at 30 bar and $1410^{\circ} \mathrm{C}$.

Hardmetal grades studied exhibit distinct combinations of single phase parameters: binder content (wt.\% binder) and carbide grain size $\left(d_{W C}\right)$, the most common features for characterizing microstructure of these materials. Binder content values are given as supplied by the manufacturer, whereas the mean grain size of the carbide phase was measured following the linear intercept method in micrographs acquired using a field emission scanning electron microscopy (FESEM) [7]. However, simultaneous variation of these parameters requires of additional two-phase normalizing ones, in order to establish rational correlations between properties and microstructure. Among them, the contiguity of the carbide phase, $C_{W C}$, and the binder mean free path, $\lambda_{C o}$, clearly stand out. The former describes the interface area fraction of WC carbides that is shared by them, whereas the latter refers to the mean size of the metallic phase. In general, an increase of the binder mean free path (or a decrease of carbide contiguity) implies a rise of the fracture toughness of the material at the expense of a decrease in hardness. Main reason behind it is the fact that thicker and less constrained (i.e. effectively more ductile) ligaments exist for cemented carbides with higher binder contents and coarser microstructures. $C_{W C}$ and $\lambda_{C o}$ were estimated from best-fit empirical equations given in the literature $[8,9]$. The designations and the corresponding microstructural parameters are listed in Table $\mathbf{1 .}$

Before testing, each surface was polished with diamond paste down to $3 \mu \mathrm{m}$, with a final polishing step with colloidal silica. Nanoindentation tests were performed on a Nanoindenter XP (MTS) with a fully calibrated Berkovich tip, and the obtained data were analyzed using the Oliver and Pharr method [10,11]. Massive nanoindentation (1400 imprints) was performed in each material in an array, at $200 \mathrm{~nm}$ of maximum displacement into surface. Every 200 indentations, tip shape quality was contrasted with a fused silica standard. The distance between imprints was kept constant and equal to 5 $\mu \mathrm{m}$ in order to avoid any overlapping effect between them. Such conditions guarantee that each individual test could be treated as an independent statistical event, as results 
were neither affected by indentation size effects nor by overlapping [6]. Observation of the imprints was done in a JEOL-7001F FESEM.

Data was treated according to the statistical method proposed by Ulm and coworkers [12-15]. Theoretical framework behind this approach is based on considering a sample composed by several $i$ distinct phases with different mechanical properties. Within this context, cemented carbides were deemed to be effectively heterogeneous materials at the microstructure scale, i.e. consisting of three phases defined by either different chemical nature (carbides and binder) or distinct carbide crystal orientation (i.e. with surface normal perpendicular to either basal or prismatic planes) [6]. In this regard, it is important to underline that the residual imprint is smaller than the size of the mean free path, as well as individual WC grains, allowing isolate the mechanical response for each phase: Co binder, $\mathrm{WC}_{\text {basal }}$ and $\mathrm{WC}_{\text {prismatic }}$ Ulm and coworker's method assumes then that distribution $\left(p_{i}\right)$ of the mechanical properties $(H)$ of each phase follows a Gaussian distribution as follows:

$$
p_{i}=\frac{1}{\sqrt{2 \pi \sigma_{i}^{2}}} e^{\left(-\frac{\left[H-H_{i}\right]^{2}}{2 \sigma_{i}^{2}}\right)}
$$

where $\sigma_{i}$ is the standard deviation and $H_{i}$ is the arithmetic mean for each of the number of indentations $\left(N_{i}\right)$ done on the material phases $(i)$. Then, the cumulative distribution function $(\mathrm{CDF})$ using a special sigmoidal shape error function can be written as follows:

$$
C D F=\sum_{i} \frac{1}{2} f_{i} e r f\left(\frac{H-H_{i}}{\sqrt{2} \sigma_{i}}\right)
$$

The fitting process was programmed to be completed when $\chi^{2}$ tolerance was less than 1 x $10^{-15}$, with a final coefficient of determination $\left(\mathrm{R}^{2}\right)$ value higher than 0.99 .

Finally, it should be noticed that length scale ratio between nanoindentation depth and binder mean free path is relatively high (about 0.5). Thus, surrounding carbides are expected to affect small-scale properties determined for the metallic phase. Accordingly, reliable assessment of the intrinsic hardness for the constrained cobalt requires its deconvolution from the values determined above. It was done by implementing the thin film model proposed by Korsunsky et al. [16], under consideration of the binder as a layer deposited onto a carbide particle, according to: 


$$
H_{C}=H_{S}+\frac{H_{f}-H_{S}}{1+k \beta^{2}}
$$

where $H_{c}$ (WC-Co composite), $H_{f}$ (Co binder) and $H_{s}$ (WC particle) are the composite, film and substrate hardness, respectively; while $\beta$ is the relative indentation depth and $k$ is a constant related to the film thickness. It permits to extract intrinsic harness values for the constrained cobalt binder, without the influence of the surrounding WC particles.

\section{Results and discussion}

Figure 1 shows an image of an area of the $10 \mathrm{CoC}$ sample where several residual imprints can clearly be seen. In Figure 2, the hardness histogram for the 10CoC grade with a constant bin size of $1 \mathrm{GPa}$ is presented. Three peaks, centered at around 9,20 and $27 \mathrm{GPa}$, may be discerned. The highest peak values are related to the prismatic and basal planes for the WC grains, in concordance with previous works [17-22], whereas the lowest values correspond to the metallic binder. In Figure 3, the statistical fit to the hardness of the cobalt phase for the different grades is presented. Cobalt peak moves to higher hardness as the mean free path $\left(\lambda_{C o}\right)$ decreases, showing hardening of the binder as carbide constraining increases. Hardness varies between $11.5 \pm 3.7$ and $8.9 \pm 2.5$ $\mathrm{GPa}$, for grades $11 \mathrm{CoM}$ and $15 \mathrm{CoC}$, respectively.

As it was referred in the previous section, the experimental hardness measurements of the constrained cobalt may be affected by the surrounding carbides. While it is not possible to correct each single experimental point because the degree of influence on each individual nanoindentation is unknown, the average values may be corrected by the average interference of the surrounding carbides. In this respect, the hardness of the Co phase was deconvoluted by implementing the thin film model proposed by Korsunsky et al. [16]. Although the case here studied does not correspond exactly with a thin film, the lateral contributions to the response are small, because the acute angle of the Berkovich indenter $\left(142.3^{\circ}\right)$ makes the stiffness in the normal direction the dominant one in the response [23]. Corrected intrinsic hardness values resulted to be ranged between 30-40 \% lower than those directly extracted from statistical analysis of data shown in Figure 3.

The flow stress $\left(\sigma_{y}\right)$ for the constrained metallic binder has been calculated from the ratio between the intrinsic hardness data and a constraint factor, reported to range from 3 to 4 for WC-Co materials [24] and considering a Vickers indenter geometry. However, the intrinsic hardness has been here determined by means of a Berkovich tip; 
thus, an additional geometrical correction factor of 0.9 must be employed [25]. Flow stress determined for each hardmetal grade is plotted in Figure 4 as a function of $\lambda_{C o}{ }^{-1 / 2}$, i.e. following a Hall-Petch relationship. In this graph, $\sigma_{y}$ values for an unconstrained cobalt alloy and a WC-Co grade with very small $\lambda_{C o}(\sim 0.048 \mu \mathrm{m})$ have been included. The yield stress for the unconstrained cobalt has been directly taken from data measured on dilute Co-W-C alloys, as reported by Roebuck et al. [26]. On the other hand, $\sigma_{y}$ values for the totally constrained grade have been assumed as the intrinsic hardness corresponding to the prismatic plane for the WC particles, i.e. the predominant orientation for the carbide phase, as discerned in Figure 2. Reliable hardness and $\sigma_{y}$ values for hardmetal grades with $\lambda_{C o}$ lower than $70 \mathrm{~nm}$ could not be determined in the experimental apparatus used, because typical Berkovick indenter radius are in the order of $100-200 \mathrm{~nm}$. As depicted in Figure 4, the flow stress follows a linear trend with the reciprocal of the square root for the mean free path. This representation allows determining the onset of plastic flow in the soft constrained metallic phase, through a Hall-Petch relationship as:

$\sigma_{y}=\sigma_{y}^{0}+\frac{k_{y}}{\lambda_{c o}^{2}}$

where $\sigma_{y}^{0}$ is specified as the friction resistance for dislocation movement within the polycrystalline grains; and $k_{y}$ is described as a measurement of the local stress needed at a grain (or phase) boundary for transmission of plastic flow [27]. A mean value of 480 MPa was taken for $\sigma_{y}^{0}[2,26]$. The Hall-Petch type relationship proposed is presented in the inset of Figure 4. Best-fit value for the slope within the Hall-Petch dependence $\left(k_{y}\right)$ is $0.98 \pm 0.15 \mathrm{MPa} \cdot \mathrm{m}^{1 / 2}$. This parameter is in between the $k_{y}$ values determined separately for the two phases, i.e. $~ 2.13 \mathrm{MPa} \cdot \mathrm{m}^{1 / 2}$ for $\mathrm{WC}[28]$ and $\sim 0.2 \mathrm{MPa} \cdot \mathrm{m}^{1 / 2}$ for bulk Co-alloys [26]. The finding of relatively higher $k_{y}$ values for the constrained binder, with respect to those determined for the polycrystalline bulk alloy, is in agreement with estimations reported by other authors $[2,28]$. This must be related to the higher efficiency of $\mathrm{WC} / \mathrm{Co}$ (hard/soft) phase boundaries, as compared to simple interfaces between grains of the same soft phase, as obstacles to dislocations movement in the metallic binder. Such a two-phase Hall-Petch strengthening effect also concords with trends reported by other authors on dual-phase bronzes and brasses [29], but here is more pronounced as a result of the large dissimilar properties between the involved phases (ceramic and metal). From a practical viewpoint, the findings presented are also useful to understand and rationalize the exceptional fracture toughness levels exhibited 
by cemented carbides. In this regard, it should be recalled that reinforcement by crackbridging from ductile Co ligaments is the main toughening mechanism for the brittle material (WC) [2]. Within this context, the constraint level exerted by the carbides on the metal phase becomes critical for optimizing microstructural design of hardmetals, as it finally defines the maximum stress level that may be supported by the strongly bonded ductile ligaments developed at the wake of propagating cracks [30,31].

\section{Conclusions}

Massive nanoindentation, statistical analysis of the experimental data and implementation of an established thin film model have been combined to successfully assess microstructural effects on the small-scale hardness and flow stress of the constrained metallic binder within WC-Co cemented carbides. Hall-Petch relationship for these materials has been analysed on the basis of the binder mean free path, a twophase normalizing parameter defined here as the effective microstructural length scale for studying phase boundary strengthening. It is found that flow stress of the constrained binder exhibits a linear dependence with the inverse square root of the binder thickness. Best-fit of experimental data yields a Hall-Petch slope, $k_{y}$, of $0.98 \pm$ $0.15 \mathrm{MPa} \cdot \mathrm{m}^{1 / 2}$. This relatively high value determined for $k_{y}$, as compared to those reported for polycrystalline bulk alloys, points out the higher strength of phase boundaries in impeding dislocation motion than simple grain boundaries. This is particularly true in the case of cemented carbides, where a soft ductile phase is surrounded by an extremely hard ceramic one; and thus, constraining effects translates into quite effective toughening by ductile ligament reinforcement. From a characterization viewpoint, the protocol implemented has shown to be a noteworthy tool to study the small-scale plastic properties of ceramic-metal composites, where probing a single phase with reliability may not be straightforward.

\section{Acknowledgements}

The authors would like to acknowledge Sandvik Hyperion for kind supply of the specimens studied as well as for its continuous support of CIEFMA's research group at UPC. They greatly appreciate useful discussion of the experimental results with Professor R.W. Armstrong. The current study was supported by the Spanish Ministerio de Economía y Competitividad through Grant MAT2015-70780-C4-3-P. Dr. J. J. Roa 
would like to thank the Juan de la Cierva Programme (Grant number JCI-2012-14454) for its financial support.

\section{References}

[1] H.E. Exner, Physical and chemical nature of cemented carbides, Int Met Rev 24 (1979) 149-173.

[2] L.S. Sigl, H.F. Fischmeister, On the fracture toughness of cemented carbides, Acta Metall 36 (1988) 887-897.

[3] A.G. Evans, R.M. McMeeking, On the toughnening of ceramics by strong reinforcements, Acta Metall 34 (1986) 2435-2441.

[4] M.F. Ashby, F.J. Blunt, M. Bannister, Flow characteristics of highly constrained metal wires, Acta Metall 37 (1989) 1847-1857.

[5] J. Riesch, J.-Y. Buffiere, T. Höschenm, M. di Michiel, M. Scheel, C. Linsmeier, J.H. You, In situ synchrotron tomography estimation of toughening effect by semi-ductile fibre reinforcement in a tungsten-fibre-reinforced tungsten composite system, Acta Mater 61 (2013) 7060-7071.

[6] J.J. Roa, E. Jiménez-Piqué, C. Verge, J.M. Tarragó, A. Mateo, J. Fair, L.Llanes, Intrinsic hardness of constitutive phases in WC-Co composites: Nanoindentation testing, statistical analysis, WC crystal orientation effects and flow stress for the constrained metallic binder, J Eur Ceram Soc 35 (2015) 3419-3425.

[7] ISO 4499-2 Hardmetals - Metallographic determination of microstructure. Part 2: Measurement of WC grain size, Geneva, Switzerland, 2008.

[8] B. Roebuck, E.A. Almond, Deformation and fracture processes and the physical metallurgy of WC-Co hardmetals, Int Mater Rev 33 (1980) 90-110.

[9] J.M. Tarragó, D. Coureaux, Y. Torres, F. Wu, I. Al.Dawery, L.Llanes, Implementation of an effective time-saving two-stage methodology for microstructural characterization of cemented carbides, Int J Refract Met Hard Mater 55 (2016) 80-86. 
[10] W.C. Oliver, G.M. Pharr, Improved technique for determining hardness and elastic modulus using load and displacement sensing indentation experiments, J Mater Res 7 (1992) 1564-1580.

[11] W.C. Oliver, G.M. Pharr, Measurement of hardness and elastic modulus by instrumented indentation: Advances in understanding and refinements to methodology, J Mater Res 19 (2004) 3-20.

[12] G. Constantinides, F.-J. Ulm, K. Van Vliet, On the use of nanoindentation for cementitious materials, Mater Struct 36 (2003) 191-196.

[13] G. Constantinides, K.S.R. Chandran, F.-J. Ulm, K. Van Vliet, Grid indentation analysis of composite microstructure and mechanics: Principles and validation, Mater Sci Eng A 430 (2006) 189-202.

[14] G. Constantinides, F.-J. Ulm, The nanogranular nature of C-S-H, J Mech Phys Solids 55 (2006) 64-90.

[15] F.-J. Ulm, M. Vandamme, C. Bobko, J.A. Ortega, K. Tai, J.C. Ortiz, Statistical indentation techniques for hydrated nanocomposites: Concrete, bone, and shale, J Am Ceram Soc 90 (2007) 2677-2692.

[16] A.M. Korsunsky, M.R. McGurk, S.J. Bull, T.F. Page, On the hardness of coated systems, Surf Coat Technol 99 (1998) 171-183.

[17] D.N. French, D. Thomas, Hardness anisotropy and slip in WC crystals, Trans AIME 233 (1965) 950-952.

[18] M. Lee, High-temperature properties of WC-Co cemented carbides, Metall Trans A 14A (1983) 1625-1629.

[19] N. Cuadrado, D. Casellas, L. Llanes, I. González, J. Caro, Effect of crystal anisotropy on the mechanical properties of WC embedded in WC-Co cemented carbides, Proceedings Euro PM2011-Hard Materials 2 (2011) 215-220, Barcelona. 
[20] B. Roebuck, P. Klose, K.P. Mingard, Hardness of hexagonal tungsten carbide crystals as a function of orientation, Acta Mater 60 (2012) 6131-6143.

[21] A. Duszová, R. Halgas, M. Bl'anda, P. Hvizdos, F. Lofaj, J. Dusza, J. Morgiel, Nanoindentation of WC-Co hardmetals, J Eur Ceram Soc 33 (2013) 2227-2232.

[22] T. Csanádi, M. Bl'anda, N.Q. Chinh, P. Hvizdos, J. Dusza, Orientation-dependent hardness and nanoindentation-induced deformation mechanisms of WC crystals, Acta Mater 83 (2015) 397-407.

[23] C.A. Botero, E. Jiménez-Piqué, C. Baudín, N. Salán, L. Llanes, Nanoindentation of $\mathrm{Al}_{2} \mathrm{O}_{3} / \mathrm{Al}_{2} \mathrm{TiO}_{5}$ composites: Small-scale mechanical properties of $\mathrm{Al}_{2} \mathrm{TiO}_{5}$ as reinforcement phase, J Eur Ceram Soc 32 (2012) 3723-3731.

[24] H. Doi, Y. Fujiwara, K. Miyake, Mechanism of plastic deformation and dislocation damping of cemented carbides, Trans Met Soc AIME 245 (1969) 1457-1470.

[25] O. Casals, J. Alcalá, The duality in mechanical property extractions from Vickers and Berkovich instrumented indentation experiments, Acta Mater 53 (2005) 3545-3561. [26] B. Roebuck, E.A. Almond, A.M. Cottenden, The influence of composition, phase transformation and varying the relative F.C.C. and H.C.P. phase contents on the properties of dilute CoWC alloys, Mater Sci Eng 66 (1984) 179-194.

[27] R.W. Armstrong, 60 years of Hall-Petch: Past to present nano-scale connections, Mat Trans 55 (2014) 2-12.

[28] H.C. Lee, J. Gurland, Hardness and deformation of cemented tungsten carbide, Mater Sci Eng 33 (1978) 125-133.

[29] E. Werner, H.P. Stüwe, Phase boundaries as obstacles to dislocation motion, Mater Sci Eng 68 (1984) 175-182.

[30] J.M. Tarragó, E. Jiménez-Piqué, L. Schneider, D. Casellas, I. Y. Torres, L. Llanes, FIB/FESEM experimental and analytical assessment of R-curve behavior of WC-Co cemented carbides, Mater Sci Eng A 645 (2015) 142-149. 
[31] J.M. Tarragó, D. Coureaux, Y. Torres, D. Casellas, I. Al.Dawery, L. Schneider, L. Llanes, Microstructural effects on the R-curve behavior of WC-Co cemented carbides, Mater Design 97 (2016) 492-501. 


\title{
Hall- Petch strengthening of the constrained metallic binder in $\mathrm{WC}-\mathrm{Co}$ cemented carbides: Experimental assessment by means of massive nanoindentation and statistical analysis
}

\author{
J. J. Roa ${ }^{1,2, *}$ E. Jiménez-Piqué ${ }^{1,2}$, J. M. Tarragó ${ }^{1,2}$, D. A. Sandoval ${ }^{1,2}$, A. Mateo ${ }^{1,2}$, J. \\ Fair $^{3}$, L. Llanes ${ }^{1,2}$ \\ ${ }^{1}$ CIEFMA-Departament de Ciència del Materials i Enginyeria Metal·lúrgica, \\ Universitat Politècnica de Catalunya, Campus Diagonal Besòs (EEBE). 08019 \\ Barcelona, Spain \\ ${ }^{2}$ CRnE, Universitat Politècnica de Catalunya, Campus Diagonal Besòs (EEBE). 08019, \\ Spain \\ ${ }^{3}$ Sandvik Hyperion, Coventry CV4 0XG, United Kingdom \\ * Corresponding author, e-mail: joan.josep.roa@upc.edu \\ Phone: +34 9340107 21; Fax: +34 934016706
}

\begin{abstract}
WC-Co cemented carbides are composites constituted for two interpenetrating networks. In this work, it is attempted by combining massive nanoindentation, statistical analysis, and implementation of a thin film model for deconvolution of the intrinsic hardness and flow stress of the metallic phase. Plotting of the experimentally data as a function of the binder mean free path results in a Hall-Petch strengthening relationship with a slope $\left(k_{y}\right)$ of $0.98 \mathrm{MPa} \cdot \mathrm{m}^{1 / 2}$. This value points out the effectiveness of WC-Co phase boundaries as strong obstacles to slip propagation; and thus, for toughening of brittle phase by means of crack-bridging ductile reinforcement.
\end{abstract}

Keywords: nanoindentation; composites; Hall-Petch relationship; phase boundary strengthening

\section{Introduction}

WC-Co cemented carbides, usually referred to as hardmetals, are established forefront materials for tools, structural components and wear parts with stringent requirements. They exhibit an exceptional combination of strength, toughness and wear resistance as a result of the extremely different properties of their two interpenetrating constitutive 
phases: hard, brittle carbides and a soft, ductile metallic binder. Historically, the ever increasing implementation of hardmetals has mainly taken place on the basis of replacement of steels in machining tools. Main reasons for it are the higher hardness and improved wear resistance at tool tip temperatures of the former, as compared to those of the latter. However, the range of applications for cemented carbides is (and attempts to be) much wider: from tools used for drilling and mining operations, though dies employed in the forging and stamping industries, to precision parts used in the medical, electronic, aerospace and automobile industries. Within this evolution trend, most of their emerging and/or to be consolidated applications require a higher relevance of toughness, relative to that of hardness, for enhancing material performance. In this regard, the flow stress of the constrained metallic phase is a key parameter in the effective toughening of cemented carbides [1-5]. However, direct measurement of such mechanical parameter, e.g. by nanoindentation, is not trivial. On the one hand, effective yield stress of the binder is strongly dependent on the constrainment from the hard particles. On the other hand, the effective length scale (submicrometric) of the metallic phase is quite small and the geometry of the WC is complex. Therefore, when directly probing the metallic phase by nanoindentation, the contribution of the hard phase becomes unclear, as the amount of cobalt under the indentation is unknown.

In this work, microstructural effects on the flow stress of the constrained metallic binder within different hardmetal grades are studied. It is done on the basis that experimental and statistical nanoindentation techniques can be successfully implemented for assessment and analysis of the small-scale properties intrinsic to the constitutive phases of WC-Co cemented carbides. Such approach has, been recently validated for WC-Co cemented carbides by the authors of this study [6]. Statistical analysis of the experimental data is followed by deconvolution of the influence of the hard phase on the average values measured for the soft one, by using an established thin film model. Yield stress of the constrained binder is then calculated through simple conversion of the intrinsic hardness measured for this phase. Finally, a Hall-Petch relationship is assessed for the flow stress determined for the constrained binder, using the binder mean free path as the effective microstructural length scale for studying phase boundary strengthening.

\section{Experimental procedure}


Four microstructurally different WC-Co composites were supplied by Sandvik Hyperion (Coventry, United Kingdom). Materials were made using conventional laboratory based powder metallurgy methods. Powders were initially mixed in $100 \mathrm{~g}$ batches in 0.251 carbide lined mills using WC and Co metal powders in the appropriate ratio. They were ball milled during 8 hours, and then pressed into compacts of dimensions $25 \mathrm{~mm}$ x $5 \mathrm{~mm}$ x $5 \mathrm{~mm}$ approximately. Finally, they were sinter-HIPed at 30 bar and $1410^{\circ} \mathrm{C}$.

Hardmetal grades studied exhibit distinct combinations of single phase parameters: binder content (wt.\% binder) and carbide grain size $\left(d_{W C}\right)$, the most common features for characterizing microstructure of these materials. Binder content values are given as supplied by the manufacturer, whereas the mean grain size of the carbide phase was measured following the linear intercept method in micrographs acquired using a field emission scanning electron microscopy (FESEM) [7]. However, simultaneous variation of these parameters requires of additional two-phase normalizing ones, in order to establish rational correlations between properties and microstructure. Among them, the contiguity of the carbide phase, $C_{W C}$, and the binder mean free path, $\lambda_{C o}$, clearly stand out. The former describes the interface area fraction of WC carbides that is shared by them, whereas the latter refers to the mean size of the metallic phase. In general, an increase of the binder mean free path (or a decrease of carbide contiguity) implies a rise of the fracture toughness of the material at the expense of a decrease in hardness. Main reason behind it is the fact that thicker and less constrained (i.e. effectively more ductile) ligaments exist for cemented carbides with higher binder contents and coarser microstructures. $C_{W C}$ and $\lambda_{C o}$ were estimated from best-fit empirical equations given in the literature $[8,9]$. The designations and the corresponding microstructural parameters are listed in Table 1.

Before testing, each surface was polished with diamond paste down to $3 \mu \mathrm{m}$, with a final polishing step with colloidal silica. Nanoindentation tests were performed on a Nanoindenter XP (MTS) with a fully calibrated Berkovich tip, and the obtained data were analyzed using the Oliver and Pharr method [10,11]. Massive nanoindentation (1400 imprints) was performed in each material in an array, at $200 \mathrm{~nm}$ of maximum displacement into surface. Every 200 indentations, tip shape quality was contrasted with a fused silica standard. The distance between imprints was kept constant and equal to 5 $\mu \mathrm{m}$ in order to avoid any overlapping effect between them. Such conditions guarantee that each individual test could be treated as an independent statistical event, as results 
were neither affected by indentation size effects nor by overlapping [6]. Observation of the imprints was done in a JEOL-7001F FESEM.

Data was treated according to the statistical method proposed by Ulm and coworkers [12-15]. Theoretical framework behind this approach is based on considering a sample composed by several $i$ distinct phases with different mechanical properties. Within this context, cemented carbides were deemed to be effectively heterogeneous materials at the microstructure scale, i.e. consisting of three phases defined by either different chemical nature (carbides and binder) or distinct carbide crystal orientation (i.e. with surface normal perpendicular to either basal or prismatic planes) [6]. In this regard, it is important to underline that the residual imprint is smaller than the size of the mean free path, as well as individual WC grains, allowing isolate the mechanical response for each phase: Co binder, $\mathrm{WC}_{\text {basal }}$ and $\mathrm{WC}_{\text {prismatic }}$ Ulm and coworker's method assumes then that distribution $\left(p_{i}\right)$ of the mechanical properties $(H)$ of each phase follows a Gaussian distribution as follows:

$$
p_{i}=\frac{1}{\sqrt{2 \pi \sigma_{i}^{2}}} e^{\left(-\frac{\left[H-H_{i}\right]^{2}}{2 \sigma_{i}^{2}}\right)}
$$

where $\sigma_{i}$ is the standard deviation and $H_{i}$ is the arithmetic mean for each of the number of indentations $\left(N_{i}\right)$ done on the material phases $(i)$. Then, the cumulative distribution function $(\mathrm{CDF})$ using a special sigmoidal shape error function can be written as follows:

$$
C D F=\sum_{i} \frac{1}{2} f_{i} e r f\left(\frac{H-H_{i}}{\sqrt{2} \sigma_{i}}\right)
$$

The fitting process was programmed to be completed when $\chi^{2}$ tolerance was less than 1 x $10^{-15}$, with a final coefficient of determination $\left(\mathrm{R}^{2}\right)$ value higher than 0.99 .

Finally, it should be noticed that length scale ratio between nanoindentation depth and binder mean free path is relatively high (about 0.5 ). Thus, surrounding carbides are expected to affect small-scale properties determined for the metallic phase. Accordingly, reliable assessment of the intrinsic hardness for the constrained cobalt requires its deconvolution from the values determined above. It was done by implementing the thin film model proposed by Korsunsky et al. [16], under consideration of the binder as a layer deposited onto a carbide particle, according to: 
$H_{C}=H_{S}+\frac{H_{f}-H_{S}}{1+k \beta^{2}}$

where $H_{c}$ (WC-Co composite), $H_{f}$ (Co binder) and $H_{s}$ (WC particle) are the composite, film and substrate hardness, respectively; while $\beta$ is the relative indentation depth and $k$ is a constant related to the film thickness. It permits to extract intrinsic harness values for the constrained cobalt binder, without the influence of the surrounding WC particles.

\section{Results and discussion}

Figure 1 shows an image of an area of the 10CoC sample where several residual imprints can clearly be seen. In Figure 2, the hardness histogram for the 10CoC grade with a constant bin size of $1 \mathrm{GPa}$ is presented. Three peaks, centered at around 9, 20 and $27 \mathrm{GPa}$, may be discerned. The highest peak values are related to the prismatic and basal planes for the WC grains, in concordance with previous works [17-22], whereas the lowest values correspond to the metallic binder. In Figure 3, the statistical fit to the hardness of the cobalt phase for the different grades is presented. Cobalt peak moves to higher hardness as the mean free path $\left(\lambda_{C o}\right)$ decreases, showing hardening of the binder as carbide constraining increases. Hardness varies between $11.5 \pm 3.7$ and $8.9 \pm 2.5$ $\mathrm{GPa}$, for grades $11 \mathrm{CoM}$ and $15 \mathrm{CoC}$, respectively.

As it was referred in the previous section, the experimental hardness measurements of the constrained cobalt may be affected by the surrounding carbides. While it is not possible to correct each single experimental point because the degree of influence on each individual nanoindentation is unknown, the average values may be corrected by the average interference of the surrounding carbides. In this respect, the hardness of the Co phase was deconvoluted by implementing the thin film model proposed by Korsunsky et al. [16]. Although the case here studied does not correspond exactly with a thin film, the lateral contributions to the response are small, because the acute angle of the Berkovich indenter $\left(142.3^{\circ}\right)$ makes the stiffness in the normal direction the dominant one in the response [23]. Corrected intrinsic hardness values resulted to be ranged between 30-40\% lower than those directly extracted from statistical analysis of data shown in Figure 3.

The flow stress $\left(\sigma_{y}\right)$ for the constrained metallic binder has been calculated from the ratio between the intrinsic hardness data and a constraint factor, reported to range from 
3 to 4 for WC-Co materials [24] and considering a Vickers indenter geometry. However, the intrinsic hardness has been here determined by means of a Berkovich tip; thus, an additional geometrical correction factor of 0.9 must be employed [25]. Flow stress determined for each hardmetal grade is plotted in Figure 4 as a function of $\lambda_{C o}{ }^{-1 / 2}$, i.e. following a Hall-Petch relationship. In this graph, $\sigma_{y}$ values for an unconstrained cobalt alloy and a WC-Co grade with very small $\lambda_{C o}(\sim 0.048 \mu \mathrm{m})$ have been included. The yield stress for the unconstrained cobalt has been directly taken from data measured on dilute Co-W-C alloys, as reported by Roebuck et al. [26]. On the other hand, $\sigma_{y}$ values for the totally constrained grade have been assumed as the intrinsic hardness corresponding to the prismatic plane for the WC particles, i.e. the predominant orientation for the carbide phase, as discerned in Figure 2. Reliable hardness and $\sigma_{y}$ values for hardmetal grades with $\lambda_{C o}$ lower than $70 \mathrm{~nm}$ could not be determined in the experimental apparatus used, because typical Berkovick indenter radius are in the order of $100-200 \mathrm{~nm}$. As depicted in Figure 4, the flow stress follows a linear trend with the reciprocal of the square root for the mean free path. This representation allows determining the onset of plastic flow in the soft constrained metallic phase, through a Hall-Petch relationship as:

$$
\sigma_{y}=\sigma_{y}^{0}+\frac{k_{y}}{\lambda_{C o}^{2}}
$$

where $\sigma_{y}^{0}$ is specified as the friction resistance for dislocation movement within the polycrystalline grains; and $k_{y}$ is described as a measurement of the local stress needed at a grain (or phase) boundary for transmission of plastic flow [27]. A mean value of 480 MPa was taken for $\sigma_{y}^{0}[2,26]$. The Hall-Petch type relationship proposed is presented in the inset of Figure 4. Best-fit value for the slope within the Hall-Petch dependence $\left(k_{y}\right)$ is $0.98 \pm 0.15 \mathrm{MPa} \cdot \mathrm{m}^{1 / 2}$. This parameter is in between the $k_{y}$ values determined separately for the two phases, i.e. $~ 2.13 \mathrm{MPa} \cdot \mathrm{m}^{1 / 2}$ for $\mathrm{WC}[28]$ and $\sim 0.2 \mathrm{MPa} \cdot \mathrm{m}^{1 / 2}$ for bulk Co-alloys [26]. The finding of relatively higher $k_{y}$ values for the constrained binder, with respect to those determined for the polycrystalline bulk alloy, is in agreement with estimations reported by other authors [2,28]. This must be related to the higher efficiency of WC/Co (hard/soft) phase boundaries, as compared to simple interfaces between grains of the same soft phase, as obstacles to dislocations movement in the metallic binder. Such a two-phase Hall-Petch strengthening effect also concords with trends reported by other authors on dual-phase bronzes and brasses [29], but here is more pronounced as a result of the large dissimilar properties between the involved 
phases (ceramic and metal). From a practical viewpoint, the findings presented are also useful to understand and rationalize the exceptional fracture toughness levels exhibited by cemented carbides. In this regard, it should be recalled that reinforcement by crackbridging from ductile Co ligaments is the main toughening mechanism for the brittle material (WC) [2]. Within this context, the constraint level exerted by the carbides on the metal phase becomes critical for optimizing microstructural design of hardmetals, as it finally defines the maximum stress level that may be supported by the strongly bonded ductile ligaments developed at the wake of propagating cracks [30,31].

\section{Conclusions}

Massive nanoindentation, statistical analysis of the experimental data and implementation of an established thin film model have been combined to successfully assess microstructural effects on the small-scale hardness and flow stress of the constrained metallic binder within WC-Co cemented carbides. Hall-Petch relationship for these materials has been analysed on the basis of the binder mean free path, a twophase normalizing parameter defined here as the effective microstructural length scale for studying phase boundary strengthening. It is found that flow stress of the constrained binder exhibits a linear dependence with the inverse square root of the binder thickness. Best-fit of experimental data yields a Hall-Petch slope, $k_{y}$, of $0.98 \pm$ $0.15 \mathrm{MPa} \cdot \mathrm{m}^{1 / 2}$. This relatively high value determined for $k_{y}$, as compared to those reported for polycrystalline bulk alloys, points out the higher strength of phase boundaries in impeding dislocation motion than simple grain boundaries. This is particularly true in the case of cemented carbides, where a soft ductile phase is surrounded by an extremely hard ceramic one; and thus, constraining effects translates into quite effective toughening by ductile ligament reinforcement. From a characterization viewpoint, the protocol implemented has shown to be a noteworthy tool to study the small-scale plastic properties of ceramic-metal composites, where probing a single phase with reliability may not be straightforward.

\section{Acknowledgements}

The authors would like to acknowledge Sandvik Hyperion for kind supply of the specimens studied as well as for its continuous support of CIEFMA's research group at UPC. They greatly appreciate useful discussion of the experimental results with 
Professor R.W. Armstrong. The current study was supported by the Spanish Ministerio de Economía y Competitividad through Grant MAT2015-70780-C4-3-P. Dr. J. J. Roa would like to thank the Juan de la Cierva Programme (Grant number JCI-2012-14454) for its financial support.

\section{References}

[1] H.E. Exner, Physical and chemical nature of cemented carbides, Int Met Rev 24 (1979) 149-173.

[2] L.S. Sigl, H.F. Fischmeister, On the fracture toughness of cemented carbides, Acta Metall 36 (1988) 887-897.

[3] A.G. Evans, R.M. McMeeking, On the toughnening of ceramics by strong reinforcements, Acta Metall 34 (1986) 2435-2441.

[4] M.F. Ashby, F.J. Blunt, M. Bannister, Flow characteristics of highly constrained metal wires, Acta Metall 37 (1989) 1847-1857.

[5] J. Riesch, J.-Y. Buffiere, T. Höschenm, M. di Michiel, M. Scheel, C. Linsmeier, J.H. You, In situ synchrotron tomography estimation of toughening effect by semi-ductile fibre reinforcement in a tungsten-fibre-reinforced tungsten composite system, Acta Mater 61 (2013) 7060-7071.

[6] J.J. Roa, E. Jiménez-Piqué, C. Verge, J.M. Tarragó, A. Mateo, J. Fair, L.Llanes, Intrinsic hardness of constitutive phases in WC-Co composites: Nanoindentation testing, statistical analysis, WC crystal orientation effects and flow stress for the constrained metallic binder, J Eur Ceram Soc 35 (2015) 3419-3425.

[7] ISO 4499-2 Hardmetals - Metallographic determination of microstructure. Part 2: Measurement of WC grain size, Geneva, Switzerland, 2008.

[8] B. Roebuck, E.A. Almond, Deformation and fracture processes and the physical metallurgy of WC-Co hardmetals, Int Mater Rev 33 (1980) 90-110. 
[9] J.M. Tarragó, D. Coureaux, Y. Torres, F. Wu, I. Al.Dawery, L.Llanes, Implementation of an effective time-saving two-stage methodology for microstructural characterization of cemented carbides, Int J Refract Met Hard Mater 55 (2016) 80-86.

[10] W.C. Oliver, G.M. Pharr, Improved technique for determining hardness and elastic modulus using load and displacement sensing indentation experiments, J Mater Res 7 (1992) 1564-1580.

[11] W.C. Oliver, G.M. Pharr, Measurement of hardness and elastic modulus by instrumented indentation: Advances in understanding and refinements to methodology, J Mater Res 19 (2004) 3-20.

[12] G. Constantinides, F.-J. Ulm, K. Van Vliet, On the use of nanoindentation for cementitious materials, Mater Struct 36 (2003) 191-196.

[13] G. Constantinides, K.S.R. Chandran, F.-J. Ulm, K. Van Vliet, Grid indentation analysis of composite microstructure and mechanics: Principles and validation, Mater Sci Eng A 430 (2006) 189-202.

[14] G. Constantinides, F.-J. Ulm, The nanogranular nature of C-S-H, J Mech Phys Solids 55 (2006) 64-90.

[15] F.-J. Ulm, M. Vandamme, C. Bobko, J.A. Ortega, K. Tai, J.C. Ortiz, Statistical indentation techniques for hydrated nanocomposites: Concrete, bone, and shale, J Am Ceram Soc 90 (2007) 2677-2692.

[16] A.M. Korsunsky, M.R. McGurk, S.J. Bull, T.F. Page, On the hardness of coated systems, Surf Coat Technol 99 (1998) 171-183.

[17] D.N. French, D. Thomas, Hardness anisotropy and slip in WC crystals, Trans AIME 233 (1965) 950-952.

[18] M. Lee, High-temperature properties of WC-Co cemented carbides, Metall Trans A 14A (1983) 1625-1629. 
[19] N. Cuadrado, D. Casellas, L. Llanes, I. González, J. Caro, Effect of crystal anisotropy on the mechanical properties of WC embedded in WC-Co cemented carbides, Proceedings Euro PM2011-Hard Materials 2 (2011) 215-220, Barcelona.

[20] B. Roebuck, P. Klose, K.P. Mingard, Hardness of hexagonal tungsten carbide crystals as a function of orientation, Acta Mater 60 (2012) 6131-6143.

[21] A. Duszová, R. Halgas, M. Bl’anda, P. Hvizdos, F. Lofaj, J. Dusza, J. Morgiel, Nanoindentation of WC-Co hardmetals, J Eur Ceram Soc 33 (2013) 2227-2232.

[22] T. Csanádi, M. Bl'anda, N.Q. Chinh, P. Hvizdos, J. Dusza, Orientation-dependent hardness and nanoindentation-induced deformation mechanisms of WC crystals, Acta Mater 83 (2015) 397-407.

[23] C.A. Botero, E. Jiménez-Piqué, C. Baudín, N. Salán, L. Llanes, Nanoindentation of $\mathrm{Al}_{2} \mathrm{O}_{3} / \mathrm{Al}_{2} \mathrm{TiO}_{5}$ composites: Small-scale mechanical properties of $\mathrm{Al}_{2} \mathrm{TiO}_{5}$ as reinforcement phase, J Eur Ceram Soc 32 (2012) 3723-3731.

[24] H. Doi, Y. Fujiwara, K. Miyake, Mechanism of plastic deformation and dislocation damping of cemented carbides, Trans Met Soc AIME 245 (1969) 1457-1470.

[25] O. Casals, J. Alcalá, The duality in mechanical property extractions from Vickers and Berkovich instrumented indentation experiments, Acta Mater 53 (2005) 3545-3561. [26] B. Roebuck, E.A. Almond, A.M. Cottenden, The influence of composition, phase transformation and varying the relative F.C.C. and H.C.P. phase contents on the properties of dilute CoWC alloys, Mater Sci Eng 66 (1984) 179-194.

[27] R.W. Armstrong, 60 years of Hall-Petch: Past to present nano-scale connections, Mat Trans 55 (2014) 2-12.

[28] H.C. Lee, J. Gurland, Hardness and deformation of cemented tungsten carbide, Mater Sci Eng 33 (1978) 125-133.

[29] E. Werner, H.P. Stüwe, Phase boundaries as obstacles to dislocation motion, Mater Sci Eng 68 (1984) 175-182. 
[30] J.M. Tarragó, E. Jiménez-Piqué, L. Schneider, D. Casellas, I. Y. Torres, L. Llanes, FIB/FESEM experimental and analytical assessment of R-curve behavior of WC-Co cemented carbides, Mater Sci Eng A 645 (2015) 142-149.

[31] J.M. Tarragó, D. Coureaux, Y. Torres, D. Casellas, I. Al.Dawery, L. Schneider, L. Llanes, Microstructural effects on the R-curve behavior of WC-Co cemented carbides, Mater Design 97 (2016) 492-501. 


\section{Figure captions}

Figure 1. Micrograph of a small region of the indentation array performed at $200 \mathrm{~nm}$ of maximum indentation depth for the $10 \mathrm{CoC}$ grade. Indentations imprints are encircled.

Figure 2. Hardness histogram for the 10CoC grade determined through 1400 imprints. The simulated hardness distribution for the constrained metallic binder as well as for the WC particles (prismatic and basal plane) using the statistical fitting parameters determined though the Constantinides method [14-16] are overlap in the hardness histogram. Bin size $=1 \mu \mathrm{m}$. Similar results are obtained for the other grades.

Figure 3. Magnification of the hardness histogram of the metallic cobalt binder peak. Hardness increases as the mean free path of the WC-Co grades decreases. Bin size $=1$ $\mathrm{GPa}$.

Figure 4. Flow stress evolution against the mean free path for the different WC-Co grades. Inset represents the $\log \left(\sigma_{\mathrm{ys}}-\sigma_{\mathrm{y}}{ }^{\mathrm{o}}\right)$ vs. $\log (\lambda \mathrm{Co})$ representation in order to determine the $k_{y}$ and the $n$ exponent from the Hall-Petch relation. 


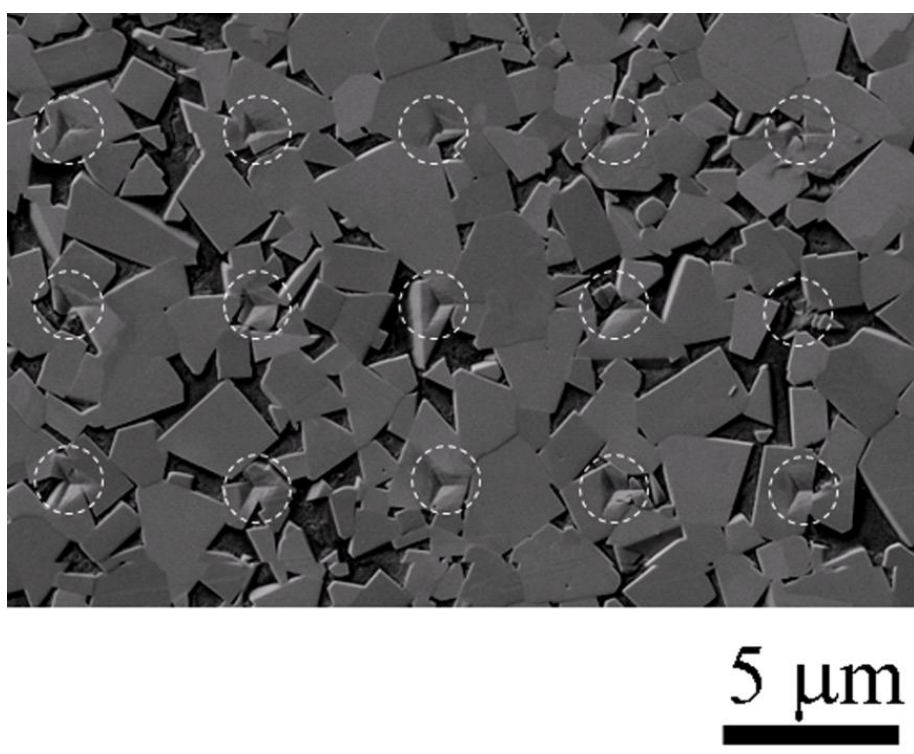

Figure 1

Figure 1

$5 \mu \mathrm{m}$ 


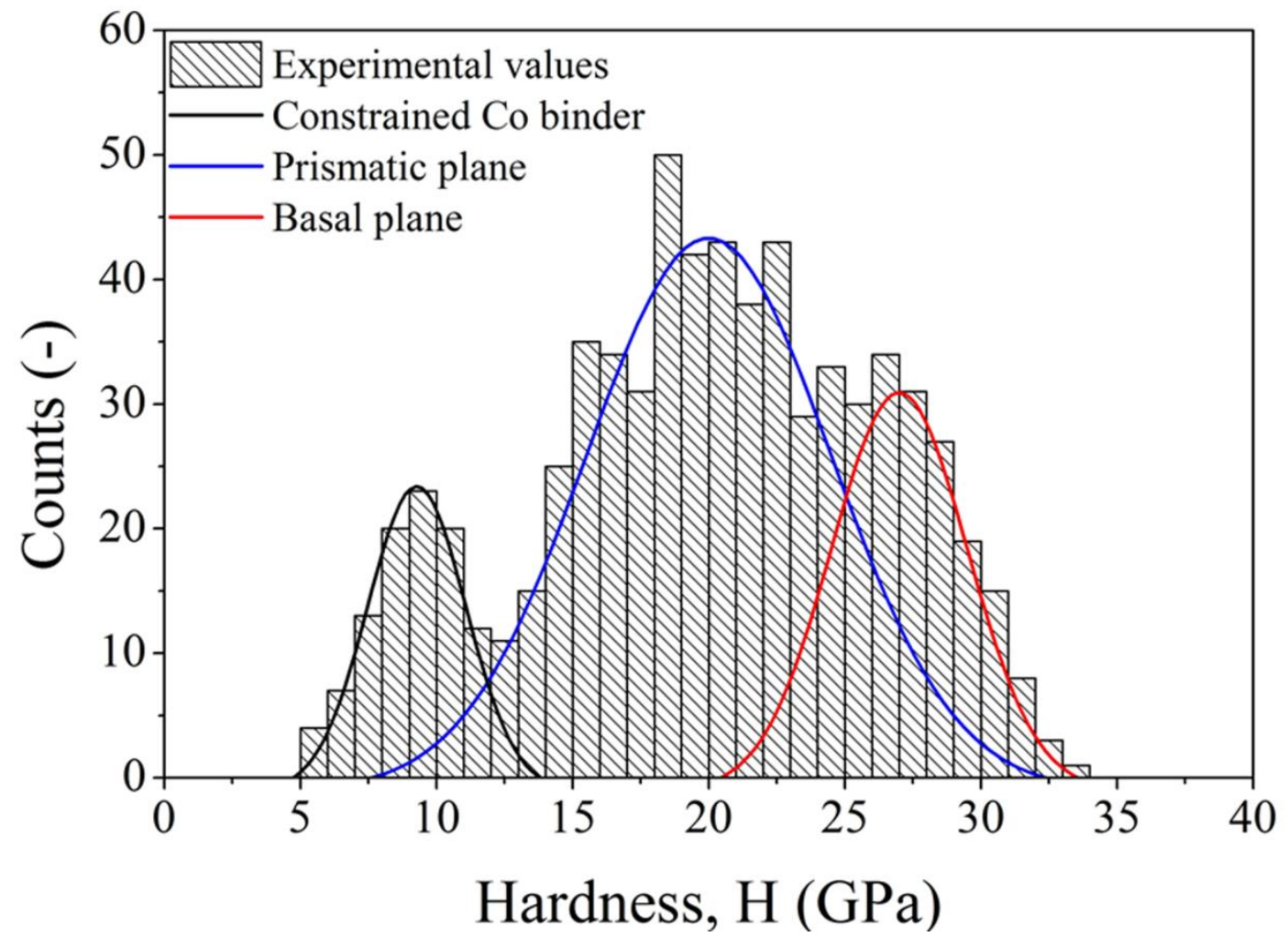

Figure 2 

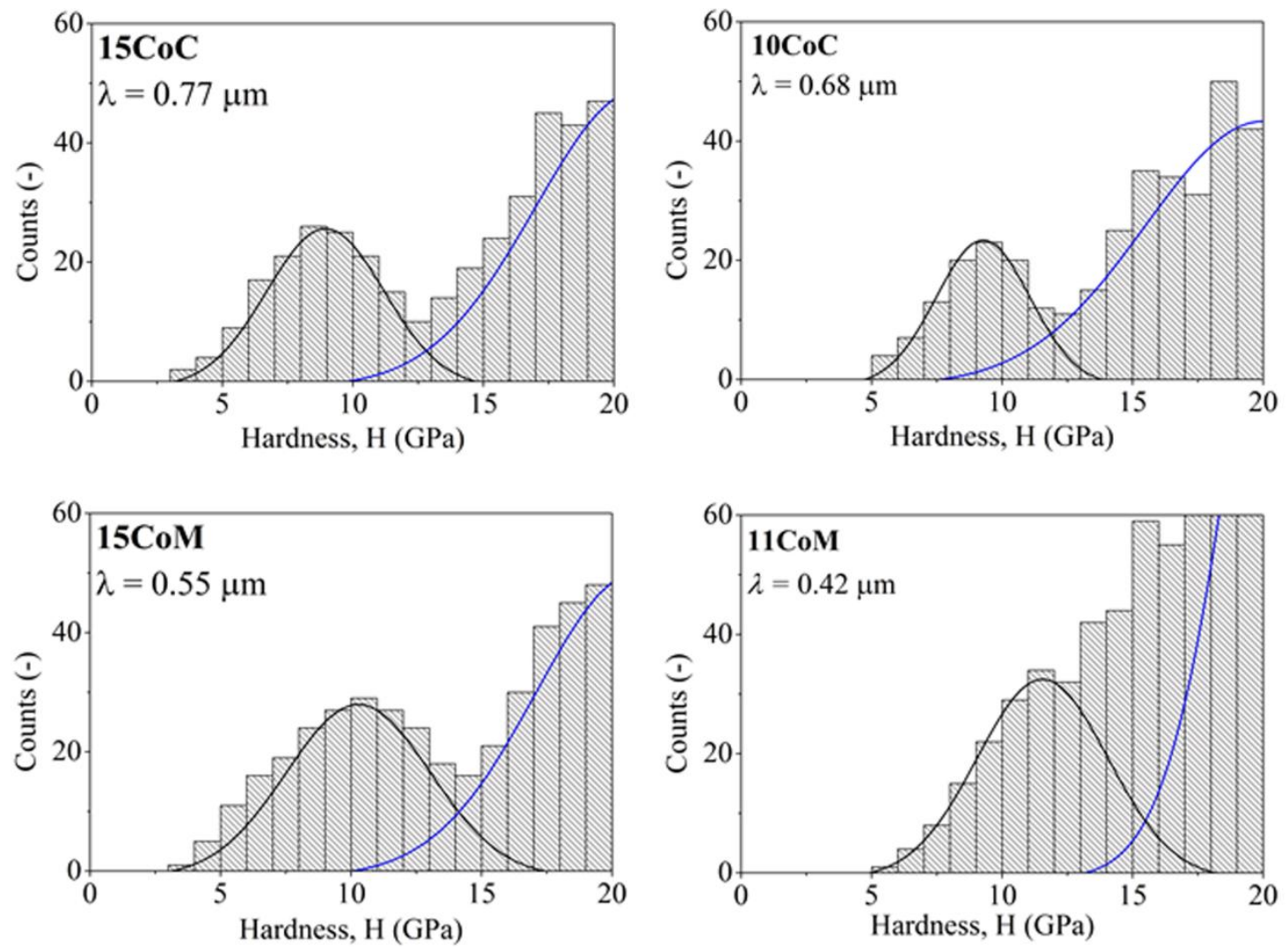

Figure 3 
Figure 4

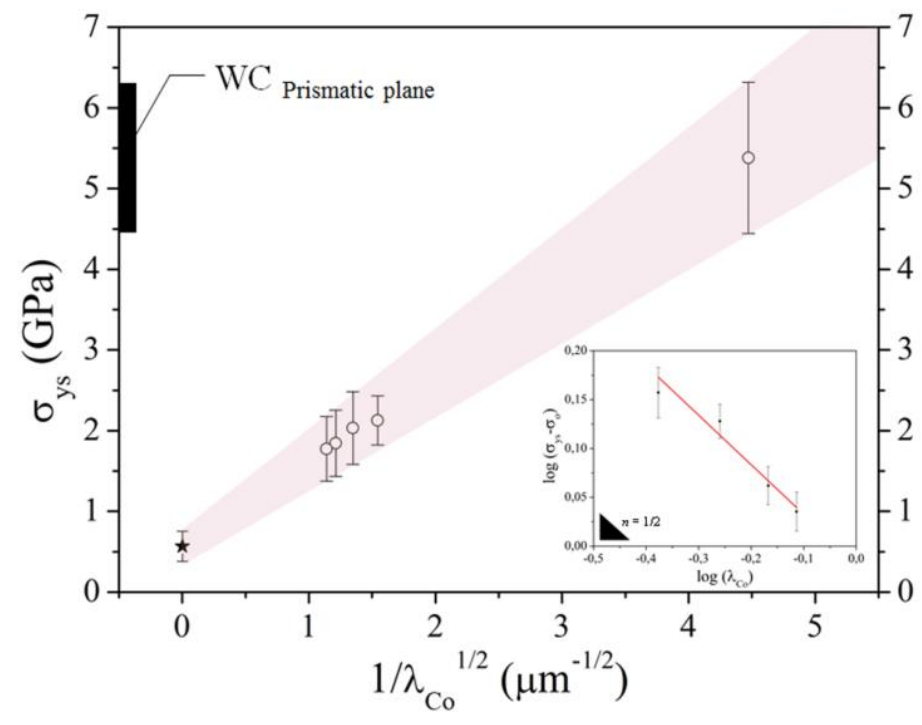

Figure 4 


\section{Table captions}

Table 1. Microstructural parameters: wt. \% binder (binder content), $d_{W C}$ (mean grain size), $C_{W C}$ (contiguity) and $\lambda_{\text {binder }}$ (binder mean free path). The label of the material refers to the amount of cobalt in the sample end the grain size, either medium (M) or coarse $(\mathrm{C})$. 
Table 1

\begin{tabular}{|l|l|l|l|l|}
\hline Grade & wt. \% binder & $d_{W C}(\mu \mathrm{m})$ & $C_{W C}$ & $\lambda_{\text {binder }}(\mu \mathrm{m})$ \\
\hline $10 \mathrm{CoC}$ & $10 \% \mathrm{Co}$ & $2.3 \pm 1.3$ & $0.31 \pm 0.11$ & $0.68 \pm 0.48$ \\
\hline $11 \mathrm{CoM}$ & $11 \% \mathrm{Co}$ & $1.1 \pm 0.7$ & $0.38 \pm 0.07$ & $0.42 \pm 0.28$ \\
\hline $15 \mathrm{CoM}$ & $15 \% \mathrm{Co}$ & $1.2 \pm 0.9$ & $0.30 \pm 0.07$ & $0.55 \pm 0.46$ \\
\hline $15 \mathrm{CoC}$ & $15 \% \mathrm{Co}$ & $1.7 \pm 1.1$ & $0.27 \pm 0.07$ & $0.77 \pm 0.54$ \\
\hline
\end{tabular}

